\title{
Prevalence of Malaria and Geohelminth Co-infection among Antenatal Women at the Federal Medical Centre and Specialist Hospital, Yola, Adamawa Sate, Nigeria
}

\section{${ }^{* 1}$ JOSEPH, R; ${ }^{2}$ CHESSED, G; ${ }^{3}$ DANIEL, L; ${ }^{2}$ HARUNA, Y; ${ }^{4}$ DEMSHEMINO, M.PH; ${ }^{5}$ BAGULA, RL}

\author{
1.Department of Science Laboratory Technology, Federal Polytechnic PMB 35 Mubi, Adamawa Nigeria. \\ 2.Department of Zoology, Moddibo Adama University of Technology, PMB 2036, Yola, Adamawa State, Nigeria. \\ 3.Department of Public Health, Adamawa State Ministry of Health, P.M.B 2017, Yola, Adamawa State Nigeria. \\ 4.Department of Biological Sciences, Federal Polytechnic PMB 35 Mubi, Adamawa Nigeria. \\ 5.Department of Vocational Education, School of Science and Technology Education, \\ Modibbo Adama University of Technology, P. M. B. 2076, Yola, Adamawa State, Nigeria. \\ *Corresponding author: josephrejoice4@gmail.com, Phone: +2347062968334
}

\begin{abstract}
Malaria and geohelminths are known to be associated with pregnancy within all age groups. The objective of this study was to determine the prevalence of malaria and geohelminths co-infection among pregnant women. The study was conducted on 252 pregnant women who came for antenatal visits at Federal Medical Center and Specialist Hospital within Yola metropolis from July to November 2015. Socio-demographic information of the pregnant women was collected. Capillary blood from finger prick was used for malaria screening by microscopy. Geohelminths were determined by stool examination using wet mount and formal ether concentration techniques. Malaria, geohelminths and co-infecion had 20.2\%,21.4\%, and $6.3 \%$ prevalence, respectively. Those within 20-24 and 25-29year age group had high rate of coinfection of $2.4 \%$ each. The results show no association between age and coinfection $\mathrm{p}<0.05$. Malaria was significant in this study at $\mathrm{p}<0.05$. The result show relatively low rate of coinfection of malaria and geohelminths prevalence. (C JASEM
\end{abstract}

https://dx.doi.org/10.4314/jasem.v21i3.7

Keywords: Prevalence, Malaria, Geohelminths, Coinfection, Hospital, Yola.

Fifty million women living in malaria-endemic areas become pregnant each year; one-half of these women live in Africa. Human malaria is caused by five species of Plasmodia: $P$. falciparum, $P$. vivax, $P$. ovale, P. malariae and P. knowlesi (WHO, 2008). Most infections are due to either P. falciparum or $P$. vivax, but multiple infections with more than one malarial species do also occur. The majority of malaria-related deaths are due to $P$. falciparum, (WHO, 2000). Malaria kills more than one million people annually most of them in Sub-Saharan Africa, where malaria is a leading cause of death for children less than five years, pregnant women and those with low socioeconomic status. (WHO, 2008). Each year, 350 to 500 million cases of malaria occur worldwide. However, the current status as reported by WHO (2013), was 219 million cases in 2010. In 2008, Nigeria holds the largest share of the world's burden of malaria, (RBM, 2008). Due to the high level of malaria transmission in Nigeria, every pregnant woman is at risk of malaria infection, the effect of which can cause little or no damage to severe life threatening damages like spontaneous abortion, stillbirths, premature delivery, low birth weight (LBW), neonatal death and maternal death $(\mathrm{FMOH}$,
2002). The North Eastern region of Nigeria has one of the highest maternal mortality ratios (MMR) in the world, and most of these deaths are preventable (Bukar et al., 2013).

Malaria remains a major environmental factor focusing on serious pregnancy complications, whose incidence and severity depend on gestational age, parity and the level of malaria endemicity. It is estimated that 10,000 women and 200,000 infants die as a result of malaria infection during pregnancy. Severe maternal anaemia, premature and low birth weight contributes to more than half of those deaths (Egwang, 2006).

The aim of the study was to determine the prevalence of malaria and geohelminth coinfection among pregnant women attending antenatal, which will provide a vital data for Adamawa State Ministry of Health towards providing necessary interventions and other organisations concerned.

\section{MATERIALS AND METHODS}

Study Area: The study was conducted at Specialist Hospital, Yola and Federal Medical Centre, Yola; 
both located in Yola North and Yola South Local Government Area (LGA) respectively, Adamawa State, North Eastern Nigeria. It lie between coordinates: $9^{\circ} 15^{\prime} \mathrm{N} 12^{\circ} 25^{\prime} \mathrm{E} / 9^{\circ} 20^{\prime} \mathrm{N} 12^{\circ} 30^{\prime} \mathrm{E}$. It covers the total area of $1,213.30 \mathrm{~km}$. Yola has a tropical climate, marked by dry and rainy seasons. The rainy season commences around May and ends in the middle or late October. Rainfall is characterized by a single maximum with a mean total rainfall of $1,113.3 \mathrm{~mm}$, August and September being the wettest months with about $25 \%$ of the total annual rainfall. The dry season starts in late October and ends in late April (Adebayo and Tukur, 1999). Temperature in Yola reaches $40^{\circ} \mathrm{C}$ around April; while minimum temperature could be as low as $18.3^{\circ} \mathrm{C}$ between December and early January which marks the harmattan period, occasioned by the north easterly trade winds.

Study Sample: Women present for delivery from July to November 2015 at the two hospitals were randomly selected based on consent to participate in the study, after which questionnaire was administered to collect socio-demographic information. A total number of 252 pregnant women were recruited for the study.

Sample collection and laboratory analyses: Finger prick blood samples were collected directly onto a clean glass slide to prepare thick and thin blood films. Additionally, fresh stool samples were collected from each pregnant woman, in a clean plastic container. The samples were immediately transported in the laboratory for processing and analysis. For malaria parasite detection, thin blood films were first fixed in methanol, both thin and thick films were stained with $10 \%$ Giemsa stain. Slides were examined under a microscope (x100 objective). A slide was considered negative if malaria parasites were not detected after examination of 200-oil immersion fields of thick smear. For positive samples, the number of parasites per 200 white blood cells (WBCs) was counted and the parasite density estimated based on an average of $8000 \mathrm{WBCs} / \mu \mathrm{l}$ of blood. (Cheesbrough, 2006).

Laboratory Procedure for Examination of Stool Samples: Saline wet mount procedure: With the aid of a dropper a drop of saline was placed on a clean slide using an applicator stick, a small portion of the stool was mixed with the normal saline. This was covered with a cover slip and mounted on the microscope. When a parasite-like object comes into view, it was closely examined and identified under high power. Saline wet mount was used for the detection of eggs and larvae of helminthes.
Formalin-ether concentration techniques and examination: Half teaspoon of faeces was thoroughly mixed in $10 \mathrm{ml}$ of water and strained through two layers of gauze in a funnel. The filtrate was centrifuged at 2,000rpm for 2 minutes. The supernatant was discarded and the sediment was resuspended in $10 \mathrm{ml}$ of physiological saline. It was again centrifuged and the supernatant was discarded. The sediment was resuspended in $7 \mathrm{ml}$ of formalin saline and allowed to stand for 10 minutes or longer for fixation, $3 \mathrm{ml}$ of ether was added. The tube was stoppered and shaken vigorously to mix. Then the stopper was removed and the tube was centrifuged at 2,000 rpm for 2 minutes. The plug of debris was detached from the side of the tube with the aid of a glass rod and the liquid was poured off leaving a small amount of formalin saline for suspension of the sediment. It was then poured on a clean glass slide, covered with cover slip and examined under microscope (Arora and Brij, 2010).

Data Analysis: Analysis was performed by SPSS version 20 statistical software package. Frequency and percentage were calculated for the study variables. Data analyses using Chi- square $\left(X^{2}\right)$ statistics was carried out to determine any statistical association between the variables at 5\% level of significance.

Ethical Considerations: Ethical permit and clearance was obtained from the ethical committee in FMC, Yola and from the ministry of Health Adamawa State and from the various hospitals through their Medical Directors. Informed consent of pregnant women participants was also obtained.

\section{RESULT AND DISCUSSION}

The demographic characteristics of the participants are shown in Table 1. House wives recorded the highest frequency of $163(64.7 \%)$, while students recorded the least frequency of $17(6.7 \%)$. Prevalence in relation to parity: Primigravida had 83 (32.9\%), secundgravidae $67(26.6 \%)$ while multigravida had the highest of $102(40.5 \%)$. In the case of formal education, those with secondary education had the highest frequency of $116(46.0 \%)$, followed by those with non-formal education 36(14.3\%), while primary education had the least of 19 (7.5\%). This study was conducted within the Yola metropolis, among a relatively homogenous population and thus these factors (disparities) may not have been large enough to be detected. Some of the limitations of this study regarding socio-demographic factors include: lack of accessing their nutritional status which has 
tremendous effects on maternal anaemia, antiparasitic drugs used by these women were not accessed, also their source of water supply and types of toilet facilities used at homes and their HIV status. Out of the 252 examined, specialist hospital yola had $142(56.3 \%)$ samples, and also had the highest prevalence of malaria parasite $(26.8 \%)$, geohelminths (22.5) and coinfection (7.0\%) while FMC yola had total frequency of $110(43.7 \%)$ with the least prevalence for malaria parasite (11.8\%), geohelminths $(20.0 \%)$ and coinfection (5.5\%) respectively. (Table 2). These differences may be due to the differences in number of data collected from each hospital and the fact that specialist hospital was more accessible to the low socioeconomic status.

A total of two hundred and fifty-two (252) blood samples obtained from pregnant women who registered for antenatal care at Federal Medical Centre, Yola $(n=110)$, and Specialist Hospital Yola $(n=142)$ which were screened for malaria and geohelminthic parasite. Out of these, 51 (20.2\%) were positive for malaria, 54(21.4\%) were positive for geohelminths while $16(6.3 \%)$ were positive for coinfection of malaria and geohelminths (Table 3 ). The findings of this study were higher than that of Yatich et al., (2010), (except in the case of coinfection which is lower) who reported a prevalence of $19.7 \%$ for $P$. falciparum, $9.1 \%$ for helminth infection and $16.6 \%$ were co-infected with malaria and geohelminths. In a similar study in Ghana, Ntui, et al. (2014), recorded 9\% malaria prevalence, 5\% prevalence of helminths.

The observed overall prevalence in this study was relatively lower than results obtained from other studies done elsewhere within the state: Shitta and Akogun (2004), recorded $48 \%$ prevalence of malaria infection, while Chessed et al., (2013) reported $56.3 \%$ prevalence of malaria and in the country at large; Ekejindu, et al. (2011) recorded $81 \%$ prevalence of malaria and $17 \%$ prevalence of Hookworm with $13 \%$ were co-infection. In 2014, Iwueze, et al. reported the prevalence of malaria among antenatal women in Onitsha to be $53.0 \%$ for $P$. falciparum. In a similar finding, Abraham, et al. (2012), reported $12.3 \%$ prevalence rate of malaria, intestinal helminth had $34.5 \%$ prevalence rate, while coinfection of $19.4 \%$ was observed; while Okorudo (2002), reported $60 \%$ prevalence of malaria among antenatal women attending clinics in Aguata L.G.A of Anambra State. The low rate of infection in this results compare to others may be due to various initiatives and awareness been created among antenatal women about the danger of these parasites and their effects.

The mean age of the women were 26.9 Years, age ranging from 16 to 45 as shown in Table 3 . The prevalence of malaria alone in relation to age shows that 30-34year age group recorded the highest rate of malaria (24.4\%), which also shown the more productive years in women were they engage in many outdoor activities at night which may increase the risk of infection. The prevalence of geohelminths alone in relation to age shows that 40-45year age group recorded the highest rate of geohelminth $(50.0 \%)$, The $40-45$ year age group recorded the highest prevalence of coinfection of malaria and geohelminth of $(16.7 \%)$, these may be due to frequent exposure to intestinal worms over time, which the body have developed resistances to it, and became asymptomatic. Malaria, geohelminths and coinfection were not significant in relation age at $\mathrm{p}>0.05$ 
Table 1: Demographic Characteristic of Study Participants

\begin{tabular}{lcc}
\hline Characteristics & No. examined & Percentage \\
\hline Age(years) & 19 & \\
$16-19$ & 74 & 7.5 \\
$20-24$ & 75 & 29.4 \\
$25-29$ & 53 & 29.8 \\
$30-34$ & 25 & 21.0 \\
$35-39$ & 6 & 9.9 \\
$40-45$ & & 2.4 \\
Occupation & 163 & 64.7 \\
House wife & 29 & 11.5 \\
Bussiness & 43 & 17.1 \\
Civil servant & 17 & 6.7 \\
Student & & \\
Parity & 83 & 32.9 \\
Primigravida & 67 & 26.6 \\
Secondigravida & 102 & 40.5 \\
Multigravida & & 14.3 \\
Formal Education & 36 & 7.5 \\
None & 19 & 46.0 \\
Primary & 116 & 32.1 \\
Secondary & 81 & 100 \\
Tertiary & 252 & \\
Total & & \\
\hline
\end{tabular}

Table 2: Prevalence of Malaria, Geohelminth and Coinfction according to Location

\begin{tabular}{ccccc|c}
\hline Location & No. Examined & Malaria & Geohelminth & Coinfection & \\
\hline FMC & $110(43.7)$ & $13(11.8)$ & $22(20.0)$ & $6(5.5)$ & \\
SPECIALIST & $142(56.3)$ & $38(26.8)$ & $32(22.5)$ & $10(7.0)$ & \\
\hline Total & $\mathbf{2 5 2}(\mathbf{1 0 0})$ & $\mathbf{5 1}(\mathbf{2 0 . 2})$ & $\mathbf{5 4}(\mathbf{2 1 . 4})$ & $\mathbf{1 6 ( 6 . 3 )}$ & \\
\hline $\mathrm{P}<0.05$, & & $\mathrm{p}>0.05$, & & $\mathrm{p}>0.05$
\end{tabular}

Table 3: Prevalence of Malaria, Geohelminth and Coinfection in relation to Age ( $\mathrm{P}>0.05)$

\begin{tabular}{ccccc}
\hline Age (Years) & No. Examined & Malaria & Positive Geohelminth & Coinfection \\
\hline $16-19$ & $19(7.5)$ & $4(21.1)$ & $5(26.3)$ & $2(10.5)$ \\
$20-24$ & $74(29.4)$ & $15(20.3)$ & $14(18.9)$ & $6(8.1)$ \\
$25-29$ & $75(29.8)$ & $13(17.3)$ & $20(26.7)$ & $6(8.0)$ \\
$30-34$ & $53(21.0)$ & $13(24.4)$ & $9(17.0)$ & $0(0.0)$ \\
$35-39$ & $25(9.9)$ & $5(20.0)$ & $3(12.0)$ & $1(4.0)$ \\
$40-45$ & $6(2.4)$ & $1(16.7)$ & $3(50.0)$ & $1(16.7)$ \\
Total & $252(100)$ & $51(20.2)$ & $54(21.4)$ & $16(6.3)$ \\
\hline
\end{tabular}

Conclusion : In conclusion, from the result obtained, prevalence of malaria, geohelminths and co-infection was lower compared to most of the documental results obtained, even though only malaria was significantly at $p>0.05$, these may imply that, antenatal routines create awareness among the pregnant women and the different interventions as observed.

Acknowledgement: We are grateful to all the pregnant women who avail themselves for this study. Also our gratitude goes to the management and laboratory staff of F M C and S H Y, for their time and guidance throughout the period of the study.

\section{REFERENCES}

Abraham, D., Mengistu, L., Girmay, M., Ababe, A., Berhanu, E. (2012). Maiaria and related outcomes in patients with intestinal helminths: a cross sectional study. BMC infectious diseases, 12:291.

Adebayo and Tukur (1999). Adamawa State in Maps. ISBN 978-35157-0-5.

Arora and Brij (2010). Medical Parasitology, CBS publishers and distributors PVT. Ltd. $3^{\text {rd }}$ (ed). ISBN: 978-81-239-1850-1. PP 233-238.

Bukar, M., Kunmanda, V., Moruppa, J., Ehalaiye, B., Takai, U., Ndonya, D. (2013). Maternal mortality at Federal Medical Centre Yola, Adamawa State; a five-year review. Annual Medical Health Science Research,3(4):568-571.

Bouyou-Akotet, M.K., Lonete-Collard, D.E., Mabikia - Manfoumbi, M., Kendjo, E., Matsiegui, P.B., Mavoungou, E. (2003). 
Prevalence of Plasmodium Falciparum Infection in Pregnant Women in Gabon. Malaria Journal.2:18.

Buseri, F.I., Uko, E.K., Jeremiah, Z.A., Usanga, E.A. (2008). Prevalence and Risk Factors of Anaemia among Pregnant women in Nigeria. Open Hematology Journal, 2:14-19.

Cheesbrough, M. (2006). District Laboratory practice in Tropical Countries part 2 (ed). Cambridge University Press, New York. Pp 320-329.

Chessed, G., Obak, E.O., Yako, A.B., Egbucha, K. (2013). Prevalence of Malaria among Pregnant Women in Yola South Local Government Area, Adamawa State, Nigeria. Global Research Journal of Science, 2(2):91-99.

Ekejindu, I.M., Okeke, E.K., Akah, B., Okpala, E., Ezeagwuna, D.A., Onwurah, O. (2011). Malaria and Hookworm Coinfection among Pregnant and Non Pregnant Women in a Semi-Urban Area in Anambra State, Nigeria. World Journal of Medical Sciences, 6 (1):33-35.

Egwang, T. (2006). Malaria and HIV Interactions and Their Implications for Public Health Policy.International Journal of Epidermiology, 27(2):296-301.

Federal Ministry of Health. (2002). Malaria Situation Analysis Document.

Iwueze, M.O., Okwusogu, M.I., Onyido, A.E., Okafor, F.C., Nwaorgu, O.C., Ukibe, S.C. (2014). Prevalence,

Intensity and Clinical Profile of Malaria among Pregnant Women Attending Antenatal Clinics in
Onitsha-North local Government Area, Anambra State, The Bioscientist, 2 (1): 17-29.

Ntui, N.A., Pauline, E. J., April, P. C., Cornelius, A. T., Kui, Z., Nana, O. W., Jonathan, K.S., Berhanu, T. (2014). Effect of Malaria and geohelminth Infection on Birth Outcomes in Kumasi, Ghana. International Journal of Tropical Disease and Health, 4(5): 582-594.

Okoroudo O. N., Mbanugo, J. I. (2002). Prevalence of plasmodium infections in pregnant women attending antenatal clinics in Aguata Local Govrnment Area, Anambra state. Nigeria Society of Parasitology 20:13

Roll Back Malaria, (2008). Key Malaria Facts.WHO, Geneva.

Shitta, K.B. and Akogun, O.B (2004). The prevalence of intestinal parasite infection among the

nomadic Fulani in Adamawa State, Nigeria. 28th Annual Conference Abstract (26) Nigerian Society of Parasitology. 20: 30.

World Health Organization. (2000). Expert committee on malaria. WHO Technical Report Series: $\quad 892: 174$.

World Health Organization (2008). World Malaria Report. World Health Organization, Switzerland. 2008. 99-101.

Yatich, J.N., Pauline, E, J., Ellen, F., Tsiri, A., Julian, C. R., John, E.E., Archer, T., Jonathan, K. S., William, O.E., Yi, J., Jonathan, H.W. (2010). The effect of malaria and intestinal helminth coinfection on birth outcome in kumasi, Ghana. American Journal of Tropical Medicine and Hygiene, 82(1):28-1191 